\title{
Penetration Enhancement Effect of Turpentine Oil on Transdermal Film of Ketorolac
}

\author{
Fu-Liang Wang ${ }^{1}$, Hong-Mei $\mathrm{Ji}^{2}$, Jian-You Zhu ${ }^{3}$, Gui-Jun $\mathrm{Xu}^{4}$, Yu-Zhong Guan ${ }^{5}$ \\ and Ye-Jun Chen ${ }^{1 *}$ \\ ${ }^{1}$ Department of Pain Medicine, ${ }^{2}$ Department of Gastroenterology, ${ }^{3}$ Department of Pathology, ${ }^{4}$ Department of Radiology, \\ ${ }^{5}$ Department of Orthopedic, Linzi People's Hospital, Zibo City, Shandong 255400, China
}

*For correspondence: Email: chenyejun335@gmail.com; Tel/Fax: 0086-533-7181956

\begin{abstract}
Purpose: To prepare transdermal films of ketorolac tromethamine (KT) and study the effect of turpentine oil as a penetration enhancer for the drug.

Methods: Transdermal films of KT were prepared with Carbopol-934 and ethyl cellulose, with turpentine oil as the penetration enhancer, using solvent evaporation method. The films were characterized for physicochemical properties, ex vivo permeation, as well as in vivo anti-inflammatory and analgesic activities in Wistar rats.

Results: The transdermal films were uniform in weight and thickness, flat, with high drug content (93.9 to $98.5 \%$ ) and of high folding endurance (134.0 to 180.0). Drug permeation through excised rat abdominal skin was prolonged, with the total drug release ranging from 58.88 to $88.98 \%$ in $24 \mathrm{~h}$. The films containing penetration enhancer showed higher drug permeation than the one without the enhancer; furthermore, drug permeation increased with increase in the concentration of the enhancer. The films were non-irritant to the skin. The transdermal films prepared with permeation enhancers showed greater anti-inflammatory activity $(87.55 \pm 2.50$ and $83.24 \pm 2.29 \%$ inhibition of rat paw edema at the end of $12 \mathrm{~h}$ for formulations F2 and F3, respectively, compared to that of the formulation without enhancer with $69.99 \%$ ) as well as greater analgesic activity (quicker onset of analgesia in $1.5 \mathrm{~h}$ with longer duration of 10 to $12 \mathrm{~h}$ ).

Conclusion: Transdermal films of ketorolac have a potential for use in the treatment of pain and inflammation. Incorporation of turpentine oil in the films enhances not only drug flux but also analgesic and anti-inflammatory activities in rats.
\end{abstract}

Keywords: Transdermal patch, Spinal cord injury, Ketorolac, Analgesic, Anti-inflammatory, Penetration enhancer, Turpentine oil

Tropical Journal of Pharmaceutical Research is indexed by Science Citation Index (SciSearch), Scopus, International Pharmaceutical Abstract, Chemical Abstracts, Embase, Index Copernicus, EBSCO, African Index Medicus, JournalSeek, Journal Citation Reports/Science Edition, Directory of Open Access Journals (DOAJ), African Journal Online, Bioline International, Open-J-Gate and Pharmacy Abstracts

\section{INTRODUCTION}

Spinal cord injury (SCl) can be very devastating. To repair the initial tissue damage, $\mathrm{SCl}$ leads to complex cellular and molecular interactions within the central nervous system $[1,2]$. Pain and inflammation drastically affect the quality of life after SCl. Chronic pain is a common and significant problem occurring after $\mathrm{SCl}$. Non- steroidal anti-inflammatory drugs (NSAIDs) are frequently suggested for musculoskeletal pain, while opioid and nonopioid analgesics are used for both types of pain [3].

It is believed that reducing inflammation can decrease secondary degeneration and the functional deficit after SCl. The conventional systemic delivery of NSAIDs is generally 
associated with the high incidence of serious gastrointestinal disturbances, more peripheral distribution (rather than the localized delivery for analgesia and anti-inflammatory effect) of drug leading to higher plasma levels and hence more adverse effects $[4,5]$. Therefore, transdermal drug delivery systems (TDDS) of NSAIDs are potential alternative measure of drug delivery with the added advantage of higher site specific delivery with low plasma concentration (leading to less adverse effects), circumventing of hepatic first pass effect, avoidance of gastric irritation/discomfort, no drug-drug interaction, prolonged drug release, controlled therapeutic responses and improved patient compliance [68].

Transdermal films/patches are a practical and feasible dosage form in that there is better patient compliance and are very suited for chronic pain and inflammation management in $\mathrm{SCl}$, arthritis and other related problems. Transdermal delivery of drugs can be enhanced through use of chemical enhancers, iontophoresis, electroporation, ultrasound, microneedles, jet injection and thermal poration [9]. The use of various penetration enhancers can improve drug flux across the skin. Some chemicals used to improve penetration across the skin include alcohols, terpenes and surfactants [10]. Turpentine oil is one of the most widely investigated penetration enhancer as it improves the transdermal flux of a variety of drugs $[9,10]$.

Ketorolac tromethamine is one of the most potent pyrrolo-pyrrole group of NSAIDs. It inhibits both cyclooxygenase-1 (COX-1) and COX-2. As it has been suggested that $\mathrm{COX}$ contributes to ischemic neuronal damage it is evident that COX inhibitors may reduce spinal cord ischemic injury [11]. Various attempts have been made to improve the bioavailability of $\mathrm{KT}\left(\mathrm{t}_{1 / 2}=4\right.$ to $6 \mathrm{~h}$ ) through various dosage forms or delivery systems including the transdermal drug delivery systems [12-15]. Therefore, the aim of the present study was to prepare the transdermal film of and determine the effect of increasing concentration of turpentine oil, used as penetration enhancer, on its properties.

\section{EXPERIMENTAL}

\section{Materials}

Ketorolac tromethamine (KT), Carbopol 934 (CP934), Polyvinyl pyrrolidone K30 (PVP-K30), Polyvinyl Alcohol, carrageenan and Turpentine Oil were purchased from Sigma Aldrich, USA. All other chemicals used were of analytical grade.

\section{Preparation of transdermal films}

Matrix type transdermal films loaded with KT were prepared using solvent evaporation technique as per Table 1.

To prepare the backing membrane, an aqueous solution of polyvinyl alcohol (4 \% w/v) was poured onto cylindrical glass molds followed by drying at $50{ }^{\circ} \mathrm{C}$ for $4 \mathrm{~h}$.

Required amount of polymers (EC and Carbopol934) were dissolved in the dichloromethane: methanol (1:1) solvent in a beaker with agitation of about 500 rpm using a magnetic stirrer. KT, din-butylphthalate (plasticizer), and turpentine oil (penetration enhancer) were added to the solution under continuous stirring. After the mixing, the solution was cast onto the PVA backing membrane on a horizontal plane and kept overnight to obtain a dry film. After complete drying, the transdermal patches of $2 \times 2 \mathrm{~cm}$ were cut, wrapped in aluminum foil and stored in desiccator till further evaluation.

\section{Physical evaluation of films}

The films were evaluated for thickness, weigh uniformity, flatness, folding endurance and moisture content (Table 2).

The average thickness (of three different site) of the film was determined using a screw-gauge (Mitutoyo MMO-25DS) in circular cast $(n=3)$. The weight of each patch $\left(4 \mathrm{~cm}^{2}\right)$ was determined $(n=3)$.

Table 1: Composition of transdermal films of Ketorolac tromethamine (KT)

\begin{tabular}{|c|c|c|c|c|}
\hline \multirow[t]{2}{*}{ Formulation code } & \multicolumn{4}{|c|}{ Ingredient } \\
\hline & $\begin{array}{c}K T^{*} \\
(\% w / w)\end{array}$ & $C P: E C^{* *}$ & $\begin{array}{c}\text { Di-n-butylphthalate)* } \\
(\% \text { w/w) }\end{array}$ & $\begin{array}{c}\text { Turpentine oil } \\
(\% \mathrm{v} / w)\end{array}$ \\
\hline F1 & 20 & $2: 1$ & 30 & - \\
\hline F2 & 20 & $2: 1$ & 30 & 0.5 \\
\hline F3 & 20 & $2: 1$ & 30 & 1.0 \\
\hline F4 & 20 & $2: 1$ & 30 & 2.0 \\
\hline
\end{tabular}


To assess the flatness of the prepared films, longitudinal strips were cut from three different location of the each film. The length of each strip after waiting for $2 \mathrm{~h}$ was measured and the variation if any was noted. The variation in length indicates the nonuniformity in flatness. Non-uniformity or constriction was calculated as in Eq 1.

Constriction $(\%)=\{(L 1-L 2) / L 1\} 100 \ldots . . .(1)$

where $L 1$ is the initial length of each strip and L2 is the final length of each strip.

Flatness was calculated as in Eq 2.

Flatness $(\%)=(100-\%$ constriction $) \ldots \ldots . .(2)$

Folding endurance was determined by repeatedly folding a small strip of size $(2 \times 2 \mathrm{~cm})$ of film at the same point until it broke. The films were first exposed to $84 \%$ relative humidity, and moisture content determined for all the films by weighing the film samples individually and kept in a desiccator containing activated silica at room temperature for $24 \mathrm{~h}$. Individual films were weighed repeatedly until they attained constant weight. Moisture content was calculated as the difference between initial and final weight with respect to the final weight, as expressed as a percentage.

\section{Drug content}

Patch from each film was dissolved in $100 \mathrm{~mL}$ methanol with continuous stirring for $2 \mathrm{~h}(\mathrm{n}=3)$. The solutions were filtered, diluted suitably and analyzed at $322 \mathrm{~nm}$ in a UV spectrophotometer (Shimadzu, UV-150-02, Seisakusho, Ltd., Kyoto, Japan) (Table 2).

\section{Scanning electron microscopy}

To assess surface morphology, SEM of the films were performed by scanning electron microscope (JEOL JSM 5600, Japan). A sample of the film was affixed on the mold and the SEM operated at $15 \mathrm{~V}$.

\section{Ex vivo permeation studies}

The ex vivo permeation studies of the films of KT through an excised rat abdominal skin treated before the experiment by trimming to clean the connective tissues and then washing with isotonic buffer pH 7.4 buffer. The experiment was carried out using a modified Franz diffusion cell. A patch of $4.0 \mathrm{~cm}^{2}$ of each formulation under study was placed in intimate contact with the excised skin. The receptor compartment of the diffusion cell was filled with $25 \mathrm{~mL}$ (such that it remained in touch with the excised skin placed at the junction of donor and receptor compartments) of $\mathrm{pH} 7.4$ phosphate buffer (containing a magnetic stirrer rotating at $100 \mathrm{rpm}$; kept at $37 \pm 1{ }^{\circ} \mathrm{C}$ by means of a water jacket around the diffusion cell). Samples ( $1 \mathrm{~mL}$ each) were withdrawn at different time intervals, filtered, diluted suitably and then analyzed using UV spectrophotometer at $322 \mathrm{~nm}$. The withdrawn sample was replaced on each occasion with an equal volume of fresh medium.

\section{In vivo studies}

Healthy male Wistar rats $(200-250 \mathrm{~g})$ were used in the studies. The rats were kept in cages in standard environmental conditions of light and temperature. The rats were allowed free access to drinking water and standard diet. The protocols of the animal study were approved by the Institutional Animal Care and Use Committee of Linzi People's Hospital (approval ref no. 20160611) and was carried out in compliance with the Directive 2010/63/EU on the handling of animals used for scientific purposes [16].

\section{Primary skin irritancy}

To assess the irritant effect or any chance of edema with the use of transdermal patches, primary skin irritancy test was performed. The healthy male rats $(200-250 \mathrm{~g})$ were divided into four groups of three rats each. A $5 \mathrm{~cm}^{2}$ area of dorsal portion of all the rats were shaved and cleaned with spirit. After $12 \mathrm{~h}$ post shaving, the non-medicated patch was applied to group I (control) using an adhesive tape USP. To group II and III (both test) transdermal patch formulation F3 and F5 were applied. To group IV (standard), $0.8 \% \mathrm{v} / \mathrm{v}$ aqueous solution of formaldehyde (irritant) was applied. The application sites were observed for any erythema and edema on skin surface for 7 days after application and the scoring was done ( 0 for none, 1 for slight, 2 for well defined, 3 for moderate and 4 for scar formation in case of erythema and 0 for none, 1 for slight, 2 for well defined, 3 for moderate and 4 for severe in case of edema). $[17,18]$.

\section{In vivo anti-inflammatory test}

The selected formulations were subjected to in vivo anti-inflammatory test using standard carrageenan-induced hind rat paw edema model. Rats were divided into four groups of three rats each. The dorsal surface of rats was shaved $12 \mathrm{~h}$ before commencing the study. Control group (group I) received non-medicated (blank) 
patches. To groups II and III, patches F3 and F5 were applied on the dorsal sides of the rats while group IV received the $\mathrm{F} 1$ (plain patch with drug but without penetration enhancer). To induce the paw edema, after half an hour of the application of patches, all the rats were injected (subplantar) with $0.1 \mathrm{~mL}$ of a $1 \% \mathrm{w} / \mathrm{v}$ homogeneous suspension of carrageenan (in double-distilled water) in the right paws. The hind paw volume was measured immediately $(0 \mathrm{~h})$ and at different time intervals, using a plethysmometer (Model 7150, UGO Basile, Italy), and expressed as percent edema relative to the initial hind paw volume. Inhibition of edema was calculated as in Eq 3.

Inhibition $(\%)=E c-E t) / E c\} 100$

where Ec is \% edema in control and Et is \% edema in test.

\section{In vivo analgesic activity}

The rats were placed on hot plate analgesiometer (MK-350 D, Japan) at $50 \pm 1{ }^{\circ} \mathrm{C}$. The transdermal film was placed on the shaved dorsal surface of rat with KT dose $(1.0 \mathrm{mg} / \mathrm{kg})$ thirty min before the beginning of the test. The time taken till the rat begins to jump or lick forepaw was determined and this time was called the reaction time which was measured at various time intervals.

\section{Statistical analysis}

The results are expressed as mean \pm standard deviation. Statistical analysis was carried out using analysis of variance (ANOVA; one way between groups and parametric ANOVA) with the aid of GraphPad Prism@ 4.0 (Graphpad
Software Inc. San Diego, CA, USA). $P<0.05$ was considered to indicate significant difference.

\section{RESULTS}

\section{Physicochemical properties of the prepared films}

The thickness, weight, folding endurance, \% moisture content and drug content of the prepared transdermal patches were determined (Table 2).

All the transdermal films showed uniform thickness ranging from $0.247 \pm 0.022$ to $0.310 \pm$ $0.012 \mathrm{~mm}$. Weight of patches (area $-4 \mathrm{~cm}^{2}$ ) of different formulations ranged from $115 \pm 0.24$ to $125 \pm 0.48 \mathrm{mg}$. Due to lack of any constriction in any of the films, it was inferred that all the films were $100 \%$ flat. Folding endurance ranged from $134.0 \pm 8.72$ to $180.0 \pm 8.10$. Percent moisture content ranged from $2.92 \pm 0.20$ to $9.46 \pm 0.42$. The formulations with penetration enhancers showed higher moisture content and the highest moisture was observed in the films having highest proportion of turpentine oil.

\section{Drug loading}

All the transdermal films showed high and uniform drug loading. The percentage drug content ranged from $93.90 \pm 2.90$ to $98.50 \pm 1.60$ $\%$ for the formulations.

\section{Surface morphology}

The SEM of the transdermal films (Fig 1) showed that drug was uniformly dispersed in the matrix of the film with some projections of drug particles on the surface of film. No difference was observed in the SEM of different formulations.

Table 2: Results of Physicochemical properties of transdermal films of ketorolac tromethamine

\begin{tabular}{lcccccc}
\hline $\begin{array}{l}\text { Formulation } \\
\text { Code }\end{array}$ & $\begin{array}{c}\text { Thickness } \\
(\mathbf{m m})\end{array}$ & $\begin{array}{c}\text { Weight } \\
\mathbf{( m g )}\end{array}$ & $\begin{array}{c}\text { Folding } \\
\text { endurance }\end{array}$ & $\begin{array}{c}\text { Flatness } \\
\mathbf{( \% )}\end{array}$ & $\begin{array}{c}\text { Moisture } \\
\text { Content } \\
(\%)\end{array}$ & $\begin{array}{c}\text { Drug } \\
\text { Loading (\%) }\end{array}$ \\
\hline F1 & 0.310 & 115 & 134 & 100 & 2.92 & 98.50 \\
& \pm 0.012 & \pm 0.24 & \pm 8.70 & & \pm 0.20 & \pm 1.60 \\
F2 & 0.252 & 124 & 140 & 100 & 4.22 & 95.62 \\
& \pm 0.022 & \pm 0.72 & \pm 3.24 & & \pm 0.22 & \pm 1.65 \\
F3 & 0.247 & 122 & 152 & 100 & 5.04 & 95.90 \\
& \pm 0.022 & \pm 0.70 & \pm 6.34 & & \pm 0.20 & \pm 0.58 \\
F4 & 0.324 & 125 & 180 & 100 & 9.46 & 93.90 \\
& \pm 0.026 & \pm 0.48 & \pm 8.12 & & \pm 0.42 & \pm 2.90 \\
\hline
\end{tabular}


(a)

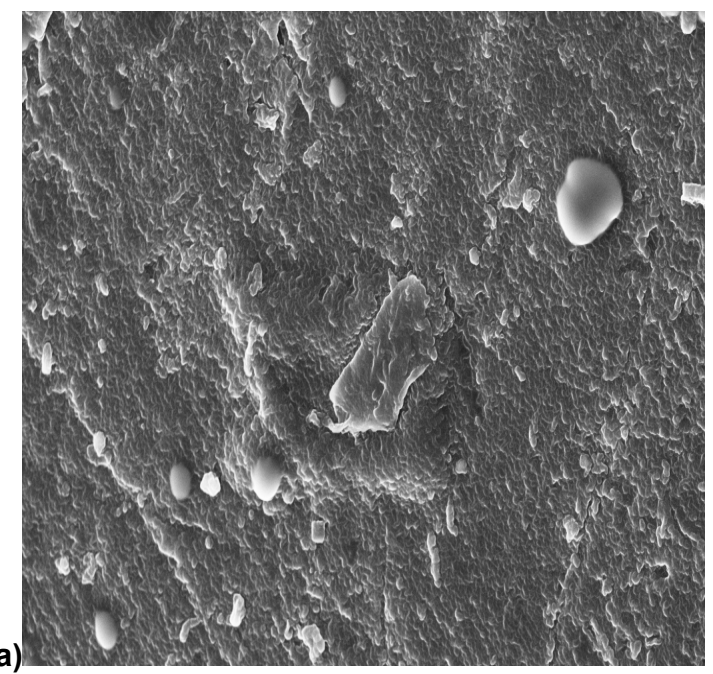

(b)



Figure 1: SEM of transdermal films of KT prepared with EC and CP-934 (a) Formulation F1 prepared without penetration enhancer (F1) and; (b) Formulation F3 prepared with penetration enhancer (turpentine oil)

\section{Drug release through excised skin}

The films prepared with penetration enhancer F2, F3 and F4 showed greater percent drug release at the end of $24 \mathrm{~h}$ (Fig 2). The drug permeation was prolonged with the transdermal film formulations prepared with turpentine oil as penetration enhancer. The permeation enhancement effect was highest for F4. However it was also observed that there was no significant difference in penetration enhancement between the transdermal films F3 and F4. The cumulative $\%$ drug permeated at the end of $24 \mathrm{~h}$ was found to be $58.88,71.22,87.09$, and $88.98 \%$ for $\mathrm{F} 1$, F2, F3and F4, respectively.

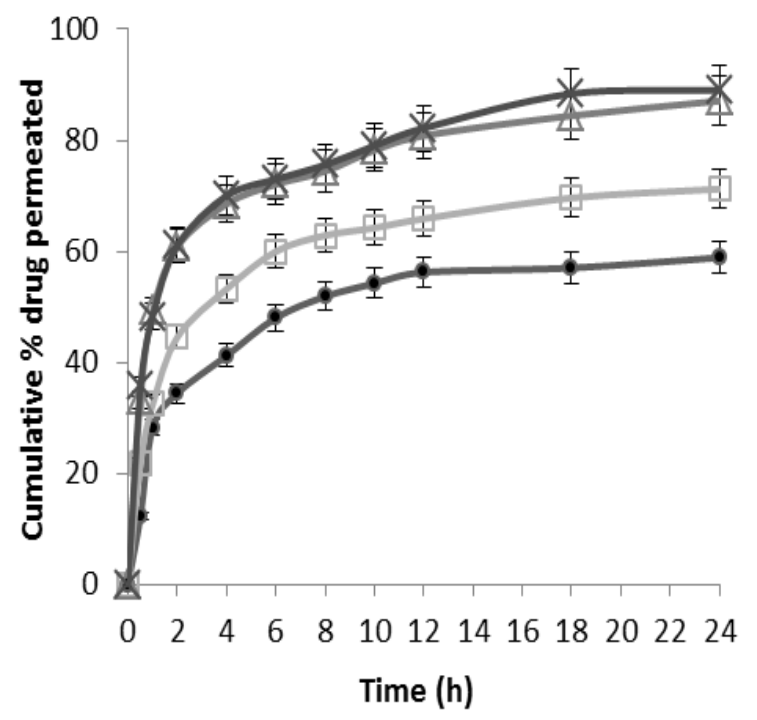

Figure 2: Ex vivo permeation study through rat abdominal skin of transdermal films of Ketorolac of F1 $(\bullet)$; F2 (口); F3 $(\Delta)$ and F4 (x)

\section{Skin irritation effect}

The prepared film formulations F1 (without enhancer) and F4 (with highest concentration of enhancer) were selected for the study. Both the formulations were found to be non-irritant to the skin because it showed erythema and edema score less than $2[17,18]$.

\section{In vivo anti-inflammatory activity}

The results showed that the patches prepared with penetration enhancers (F2 and F3) showed greater percent inhibition as compared to that of F1 (without penetration enhancer). The transdermal films showed $87.55 \pm 2.50$ and $83.24 \pm 2.29 \%$ inhibition of rat paw edema at the end of $12 \mathrm{~h}$ for formulation $\mathrm{F} 2$ and $F 3$, respectively as compared to that of formulation without enhancer (F1) with $69.99 \%$ only (Fig. 3).

\section{In vivo analgesic activity}

The maximum response (MR) to $\mathrm{KT}$ in terms of the reaction time in seconds which reflects the intensity of drug action; the time of the maximum response (TMR) and; the duration of drug action (DA) are shown in Table 4.

It was observed that F2 and F3 showed greater analgesic activity than F1. F2 and F3 (with permeation enhancer) showed faster onset of analgesia in $1.5 \mathrm{~h}$ with longer duration for 10 to $12 \mathrm{~h}$. It was also evident that analgesic activity was followed the same trend as the antiinflammatory activity of the formulation. 
Table 3: Primary skin irritation test of transdermal films of KT

\begin{tabular}{|c|c|c|c|c|c|c|c|c|}
\hline & \multicolumn{2}{|l|}{$\begin{array}{l}\text { Control } \\
\text { Group I }\end{array}$} & \multicolumn{2}{|c|}{$\begin{array}{c}\text { Test } 1 \text { (F1) } \\
\text { Group II }\end{array}$} & \multicolumn{2}{|c|}{$\begin{array}{l}\text { Test } 2 \text { (F3) } \\
\text { Group III }\end{array}$} & \multicolumn{2}{|c|}{$\begin{array}{c}\text { Standard irritant } \\
\text { Group IV }\end{array}$} \\
\hline & Erythema & Edema** & Erythema & Edema** & Erythema & Edema** & Erythema & Edema** \\
\hline & 0 & 1 & 1 & 0 & 0 & 1 & 3 & 2 \\
\hline & 1 & 1 & 0 & 1 & 1 & 0 & 3 & 1 \\
\hline & 0 & 0 & 0 & 1 & 0 & 1 & 3 & 2 \\
\hline $\begin{array}{l}\text { Averag } \\
\text { e } \pm \text { S.D }\end{array}$ & $0.34 \pm 0.58$ & $\underset{a}{0.67 \pm 0.58}$ & $0.34 \pm 0.58$ & $\underset{a}{0.67 \pm 0.58}$ & $\underset{a}{0.34 \pm 0.58}$ & $\underset{a}{0.67 \pm 0.58}$ & $3 \pm 0$ & $\begin{array}{l}1.67 \pm 0.5 \\
0\end{array}$ \\
\hline
\end{tabular}

${ }^{a} P<0.05$, significant compared with formalin; * Erythema scale: 0, none; 1, slight; 2, well defined; 3, moderate; and 4, scar formation; ${ }^{* *}$ Edema scale: 0, none; 1, slight; 2, well defined; 3, moderate; and 4, severe

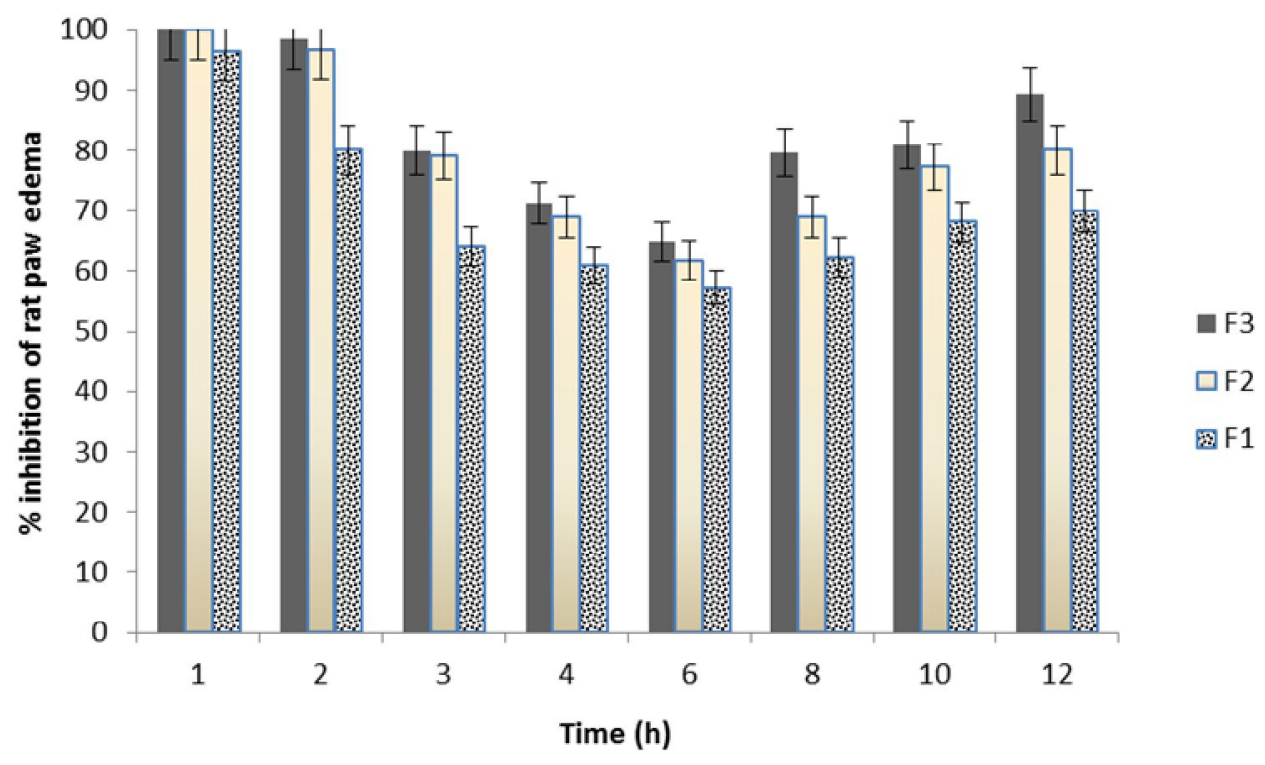

Figure 3: In vivo anti-inflammatory activity of the transdermal films of ketorolac tromethamine using carrageenan induced hind rat paw edema model. ( $p<0.05$, significant compared with control; Values corresponding to 4 to 12 $\mathrm{h}$ were significant as compared to control; $\mathrm{n}=3$ )

Table 4: In vivo analgesic activity of transdermal films of KT by hot plate method

\begin{tabular}{lccc}
\hline Formulation & $\begin{array}{c}\text { Maximum analgesic response } \\
\text { MR (s) }\end{array}$ & $\begin{array}{c}\text { Time of maximum } \\
\text { analgesic response } \\
\text { TMR }(\mathbf{h})\end{array}$ & $\begin{array}{c}\text { Duration of analgesic } \\
\text { action } \\
\text { DA (h) }\end{array}$ \\
\hline F1 & $12.5 \pm 2.02$ & 2 & 6 \\
F2 & $10.5 \pm 1.26$ & 1.5 & $>10$ \\
F3 & $8.6 \pm 1.02$ & 1.5 & $>12$ \\
\hline All values are mean $\pm S E(n=6)$ & &
\end{tabular}

\section{DISCUSSION}

In patients with $\mathrm{SCl}$, often only parenteral products can be administered to the patients. Even if the patient can take oral medication, delivering the drug in transdermal films increases the patient compliance with the added advantage of immediate and prolonged release of the drug for the effective treatment of pain and inflammation.

In this study transdermal films of KT were prepared with the aim of delivering the drugs to localized area of inflammation directly and avoiding the systemic side effects of the drug. Clinically feasible high loading of drug was obtained in all the films.

SEM photographs confirmed that for the initial drug release the surface drug might have played the role. The subsequent slow and prolonged release was from the drug present in the matrix of the film. The transdermal films prolonged drug release (up to $24 \mathrm{~h}$ ) thereby minimizing dosage frequency unlike the conventional oral drug delivery. The use of a single patch for the whole day is expected to be more patient friendly as compared to the frequent oral dosing of tablets. 
Out of these various methods of transdermal enhancement of drugs chemical enhancers has been reported to be the best in increasing the transport across the skin $[9,10]$. In the present study the turpentine oil increased the permeation very significantly. The increase was directly proportional to the concentration of turpentine oil and it was in good agreement with previous studies $[9,17,19]$. Previous studies have also reported the turpentine oil and the terpene based enhancers as the very promising penetration enhancer with the greater effect of increasing the flux and anti-inflammatory activity [9,20-22]. The present study also found turpentine oil as an effective penetration enhancer for the transdermal drug delivery of $\mathrm{KT}$ in the in vivo anti-inflammatory and analgesic activity both for the films with penetration enhancers (F2 and F3) as compared to that of films without enhancer (F1) [12,23]. The increasing concentration showed increased flux and increased analgesic and anti-inflammatory activity. Formulations with permeation enhancer showed more rapid onset $(1.5 \mathrm{~h})$ and longer duration of analgesia (for 10 to $12 \mathrm{~h})$. These data correlate well with ex vivo permeation data. Thus, the enhanced permeation of the drug across the skin produced greater analgesic and anti-inflammatory activities which would lead to greater benefit in SCI.

\section{CONCLUSION}

The developed transdermal film of KT has a great potential for the management of pain and inflammation associated with SCl. The transdermal films of $\mathrm{KT}$ can deliver therapeutic concentrations of the drug in a steady and prolonged manner throughout the day. Turpentine oil is a good penetration enhancer that results in improvement of drug flux.

\section{REFERENCES}

1. Thuret S, Moon LD, Gage FH. Therapeutic interventions after spinal cord injury. Nat Rev Neurosci 2006; 7: 628-643.

2. Whalley K, O'Neill P, Ferretti P. Changes in response to spinal cord injury with development: vascularization, hemorrhage and apoptosis. Neuroscience 2006; 137: 821-832.

3. Warms CAs, Turner JA, Marshall HM, and Cardenas DD. Treatments for chronic pain associated with spinal cord injuries: many are tried, few are helpful. Clin J Pain 2002;18:154-163

4. Semalty A, Semalty M, Rawat BS, Singh D, Rawat MSM. Development and physicochemical evaluation of pharmacosomes of diclofenac, Acta Pharm 2009; 59: 335-344. doi: 10.2478/v10007-009-0023-x
5. Semalty A, Semalty M, Rawat BS, Singh D, Rawat MSM. Development and evaluation of pharmacosomes of aceclofenac. Indian J Pharm Sci 2010; 72(5): 576581. doi: 10.4103/0250-474X.78523

6. Tanner T, Marks R. Delivering drugs by the transdermal route: review and comment. Skin Res Technol 2008; 14: 249-260.

7. Guy RH. Transdermal science and technology an update. Drug Deliv System 2007; 22: 442-449.

8. Bhoyar N, Giri TK, Tripathi DK, Alexander $A$ and Ajazuddin. Recent Advances in Novel Drug Delivery System Through Gels: Review. J Pharm All Health Sci 2012; 2: 21-39.DOI: 10.3923/jpahs. 2012.21.39

9. Marwah H, Garg T, Goyal AK, Rath G. Permeation enhancer strategies in transdermal drug delivery. Drug Deliv 2014; 9: 1-15. doi: 10.3109/10717544.2014.935532

10. Jantharaprapap $R$, Stagni G. Effects of penetration enhancers on in vitro permeability of meloxicam gels. Int J Pharm 2007; 343: 26-33. doi: 10.1016/j.jpharm.2007.04.011

11. Hsieh YC, Liang WY, Tsai SK, Wong CS. Intrathecal ketorolac pretreatment reduced spinal cord ischemic injury in rats. Anesth Analg 2005; 100(4):1134-9. PMID: 15781534

12. Abou el Ela AESF, Hassan MA, Maraghy DA, Ketorolac tromethamine floating beads for oral application: Characterization and in vitro/in vivo evaluation. Saudi Pharm J 2014; 22: 349-359. doi:10.1016/j.jsps.2013.06.006

13. Li C, Li C, Liu Z, Li Q, Yan X, Liu Y, Lu W. Enhancement in bioavailability of ketorolac tromethamine via intranasal in situ hydrogel based on poloxamer 407 and carrageenan. Int J Pharm 2014; 20; 474(12):123-133. doi: 10.1016/j.jpharm.2014.08.023. Epub 2014 Aug 17.

14. Gratieri T, Pujol-Bello E, Gelfuso GM, de Souza JG, Lopez RF, Kalia YN. Iontophoretic transport kinetics of ketorolac in vitro and in vivo: demonstrating local enhanced topical drug delivery to muscle. Eur J Pharm Biopharm 2014; 86(2): 219-226. doi: 10.1016/j. ejpb.2013.06.009

15. Ammar HO, Ghorab M, Mahmoud AA, Makram TS, Ghoneim AM. Rapid pain relief using transdermal film forming polymeric solution of ketorolac. Pharm Dev Technol 2013; 18(5): 1005-1016. doi: 10.3109/10837450.2011.627867.

16. European Commission [homepage on the internet]. Directive 2010/63/EU on the protection of animals used for scientific purposes [cited 2014 May 10]. Available from: http://ec.europa.eu/environment/ chemicals/lab_animals/legislation_en..htm.

17. Draize JH, Woodword G, Calvery HO. Methods for the study of irritation and toxicity of substances applied topically to the skin and mucous membranes. J Pharmacol ExpTher 1944; 82: 377-379.

18. Mamatha T, Rao VJ, Mukkanti K, Ramesh G. Development of matrix type transdermal patches of

Trop J Pharm Res, August 2015; 14(8): 1347 
lercanidipine hydrochloride physicochemical and invitro characterization. DARU 2010; 18(1): 9-16. PMid:22615587

19. Mukherjee B, Kanupriya, Mahapatra S, Das S, Patra B, sorbitan monolaurate 20 as a potential skin permeation enhancer in transdermal patches. J Appl Res 2005; 5(1): 96-108.

20. Khan NR, Khan GM, Khan AR, Wahab A, Asghar MJ, Akhlaq $M$, Hussain A. Formulation, physical, in vitro and ex vivo evaluation of diclofenac diethylamine matrix patches containing turpentine oil as penetration enhancer Afr J Pharm Pharmacol 2012; 6: 434-439. doi: 10.5897/AJPP11.888
21. Yang Z, Teng $Y$, Wang H, Hou H. Enhancement of skin permeation of bufalin by limonene via reservoir type transdermal patch: formulation design and biopharmaceutical evaluation. Int J Pharm 2013; 447(1-2): 231-240. doi: 10.1016/j.ijpharm.2013. 02.048.

22. Varman RM, Singh S. Investigation of effects of terpene skin penetration enhancers on stability and biological activity of lysozyme. AAPS PharmSciTech 2012; 13(4): 1084-1090. doi: 10.1208/s12249-012-9840-1.

23. Amberkar M, Tara S, Meena K, Smita S. Evaluation of anti-inflammatory and analgesic activities of alcoholic extract of kaempferia galangal in rats. Indian $\mathrm{J}$. Physiol Pharmacol 2011; 55: 13-24. 